\title{
Sensorial analysis of expressed human milk and its microbial load
}

\author{
Análise sensorial do leite humano ordenhado e sua carga microbiana \\ Franz R. Novak ${ }^{1}$, Ana R. Junqueira ${ }^{2}$, Manuela de S. P. C. Dias ${ }^{3}$, João A. G. Almeida ${ }^{4}$
}

\section{Resumo}

Objetivo: Verificar a existência de relação entre a presença de off-flavor e a carga de microrganismos em amostras de leite humano ordenhado rejeitadas pelo controle de qualidade de um banco de leite humano.

Métodos: Testou-se em 30 amostras de leite humano ordenhado com presença de off-flavor a ocorrência dos seguintes microrganismos: aeróbios mesófilos, psicrotróficos, proteolíticos, proteolíticos-psicrotróficos, termodúricos, termodúricospsicrotróficos, bactérias lácticas, lipolíticos, bolores e leveduras e Staphylococcus aureus, coliformes totais e coliformes termotolerantes, de acordo com métodos oficiais.

Resultados: A ocorrência percentual dos microrganismos foi a seguinte: aeróbios mesófilos $=80 \%$; psicrotróficos $=36,7 \%$; proteolíticos $=46,7 \%$; proteolíticos-psicrotróficos $=16,7 \%$; termodúricos $=6,7 \%$; termodúricos-psicrotróficos $=0 \%$; bactérias lácticas $=50 \%$; lipolíticos $=10 \%$; bolores e leveduras $=6,7 \%$; . aureus $=30 \%$; coliformes totais $=53,3 \%$; e coliformes termotolerantes $=16,7 \%$.

Conclusão: Observou-se relação consistente entre a presença de off-flavor e elevadas contagens dos microrganismos nas amostras analisadas, o que reforça a importância da pesquisa de off-flavor na seleção e no controle da qualidade dos bancos de leite humano.

J Pediatr (Rio J). 2008;84(2):181-184: Leite humano, banco de leite, controle de qualidade, microbiologia de alimentos.

\section{Introdução}

Por sua composição rica em diversos nutrientes, o leite humano ordenhado (LHO) pode se tornar um excelente meio de cultura para o desenvolvimento de diversos microrganismos. Entretanto, isso só pode ocorrer quando as barreiras bioquímicas, ou seja, os fatores de proteção imunológicos, capazes de impedir o crescimento microbiano, forem destru-

\begin{abstract}
Objective: To verify the existence of a relationship between presence of off-flavor and microorganism load in quality control rejected samples of expressed human milk from a donor milk bank.

Methods: A total of 30 samples of expressed human milk with off-flavor were tested for the occurrence of the following microorganisms: aerobic mesophilic, psycrotrophic, proteolytic, psycrotrophic proteolytic, thermoduric, psycrotrophic thermoduric, lactate and lipolytic bacteria, molds and yeasts and Staphylococcus aureus, total coliforms and thermophilic coliforms, in accordance with official methods.
\end{abstract}

Results: Percentage occurrence of microorganisms was as follows: aerobic mesophilic $=80 \%$; psycrotrophic $=36.7 \%$; proteolytic $=46.7 \%$; psycrotrophic proteolytic $=16.7 \%$; thermoduric $=6.7 \%$; psycrotrophic thermoduric $=0 \%$; lactate bacteria $=50 \%$; lipolytic $=10 \%$; molds and yeasts $=6.7 \%$; S. aureus $=30 \%$; total coliforms $=53.3 \%$; and thermophilic coliforms $=$ $16.7 \%$.

Conclusion: A consistent relationship between presence of off-flavor and elevated microorganism counting was observed in the analyzed samples. This correlation highlights the importance of off-flavor research during selection and quality control processes in human milk banks.

J Pediatr (Rio J). 2008;84(2):181-184: Human milk, milk banks, quality control, food microbiology.

ídos. Uma vez eliminados os fatores de proteção, os microrganismos passam a utilizar o LHO para o seu crescimento, gerando substâncias indesejáveis ${ }^{1}$. Além disso, o LHO apresenta grande capacidade de sorção (absorção e adsorção) de substâncias voláteis. Portanto, recomenda-se que, nos ambientes onde ocorra coleta e/ou manipulação de tais produtos, não devam existir odores pronunciados, que poderão ser incorporados ao leite, alterando seu flavor original. Por

1. Doutor. Instituto Fernandes Figueira, Fundação Oswaldo Cruz (Fiocruz), Rio de Janeiro, RJ.

2. Nutricionista, Universidade Federal Fluminense (UFF), Niterói, RJ.

3. Mestranda em Ciência de Alimentos, Instituto de Química, Universidade Federal do Rio de Janeiro (UFRJ), Rio de Janeiro, RJ.

4. Doutor. Instituto Fernandes Figueira, Fiocruz, Rio de Janeiro, RJ.

Fonte financiadora: Instituto Fernandes Figueira (Fiocruz), Rio de Janeiro, RJ.

Não foram declarados conflitos de interesse associados à publicação deste artigo.

Como citar este artigo: Novak FR, Junqueira AR, Dias MS, Almeida JA. Sensorial analysis of expressed human milk and its microbial load. J Pediatr (Rio J). 2008;84(2):181-184.

Artigo submetido em 28.05.07, aceito em 20.08.07.

doi:10.2223/JPED.1739 
isso, recomenda-se a não utilização de perfumes e cosméticos que tenham odores fortes, tanto pelas doadoras quanto pelos profissionais de saúde que manipulam $\mathrm{LHO}^{2}$.

Tecnicamente, flavor é a sensação físico-psicológica da interação de sabor e odor de um alimento. No caso do LHO, o flavor pode ser dividido em primário, quando originário da relação cloreto/lactose, e secundário, originado dos ácidos graxos e compostos voláteis ${ }^{1}$. Off-flavor é a característica anormal que surge no LHO pela sua deterioração ou contaminação por substâncias exógenas, acarretando o aparecimento de odores indesejáveis, decorrente de sua perda de qualidade $^{3}$.

A detecção de off-flavor no momento da seleção e classificação do LHO nos bancos de leite humano (BLH) é um eficiente instrumento capaz de detectar de forma rápida e segura a ocorrência de modificações físico-químicas, como rancificação, proteólise e fermentação da lactose, e a fixação de substâncias voláteis ${ }^{1}$.

Os padrões de off-flavor utilizados nos BLH foram desenvolvidos para descreverem qualitativamente os diversos tipos de decomposições que podem ter ocorrido em função da quebra de boas práticas durante os processos de coleta, transporte e estocagem ${ }^{1}$.

O presente estudo tem como objetivo estudar a ocorrência de diversos grupos de microrganismos em amostras de LHO que apresentavam off-flavor e vem complementar estudo prévio realizado em nosso serviço, que resultou na incorporação do teste na rotina dos BLH pela Agência Nacional de Vigilância Sanitária (ANVISA) ${ }^{4}$. Nesse estudo (não publicado), diversos testes físico-químicos identificaram os odores estranhos do LHO nos diferentes tipos de decomposição observados nos produtos. Assim, lipólise associou-se com odor de sabão de coco; proteólise, com cheiro de peixe; fermentação, com cheiro de coalhada; e proteólise/lipólise, com odor de ovo podre ${ }^{5}$. É importante ressaltar que não foram encontrados estudos similares na literatura.

\section{Métodos}

O estudo foi aprovado pelo Comitê de Ética em Pesquisa do Instituto Fernandes Figueira da Fundação Oswaldo Cruz, Rio de Janeiro.

Foram analisadas 30 amostras de LHO cru de diferentes doadoras do BLH do Instituto Fernandes Figueira (IFF), orientadas previamente a realizarem coleta manual do leite após lavagem das mãos com água e sabão, e das mamas apenas com água potável.

A amostragem foi efetuada após o cálculo do tamanho da amostra, partindo de uma variabilidade pré-determinada em estudos anteriores, admitindo um erro de amostragem da ordem de $0,5 \%$ e um fator $t$ de Student referente a 15 graus de liberdade e $5 \%$ de probabilidade, empregando a técnica descrita por Leite ${ }^{6}$. De acordo com esse cálculo, o número mínimo de amostras de leite para o estudo foi de 26 .
Após a coleta, os frascos eram armazenados sob congelamento por, no máximo, 15 dias na residência das doadoras, quando eram transportados sob congelamento em caixas isotérmicas revestidas com policloreto de vinila (PVC) contendo "gelo reciclável" na proporção de três volumes deste para cada volume de LHO.

Após o degelo, os produtos foram avaliados por profissionais treinados, que realizam a pesquisa de off-flavor regularmente no BLH/IFF, segundo as normas e procedimentos regulamentados pela ANVISA. Somente amostras recusadas pela ocorrência de off-flavor fizeram parte do presente estudo.

As amostras foram encaminhadas imediatamente, sob refrigeração, ao laboratório, onde foram realizadas análises microbiológicas de acordo com o Compendium of Methods for the Microbiological Examination of Foods ${ }^{7}$ e o Manual de Métodos de Análise Microbiológica de Alimentos ${ }^{8}$.

Foram determinados, por meio da técnica de contagem padrão em placas, os seguintes grupos de microrganismos: aeróbios mesófilos, psicrotróficos, proteolíticos, proteolíticospsicrotróficos, termodúricos, termodúricos-psicrotróficos, bactérias lácticas, bactérias lipolíticas, bolores e leveduras e S. aureus. Por meio da técnica de número mais provável $/ \mathrm{mL}$, foram pesquisados coliformes totais e coliformes termotolerantes.

\section{Resultados}

Das 30 amostras analisadas, uma apresentava forte odor de remédio com crescimento microbiano desprezível. As demais apresentaram crescimentos vigorosos de um ou vários grupos de microbianos.

Na Tabela 1, pode-se observar a porcentagem de contaminação pelos diferentes grupos de microrganismos pesquisados das amostras de LHO rejeitadas pela presença de off-flavor.

Os microrganismos aeróbios mesófilos ocorreram em número igual ou superior a $10^{4} \mathrm{UFC} / \mathrm{mL}$ e, em 24 amostras, observaram-se contagens da ordem de $10^{4}$ a $10^{8} \mathrm{UFC} / \mathrm{mL}$. Do total, 11 amostras apresentaram microrganismos psicrotróficos com contagens que variavam de $10^{3}$ a $10^{7} \mathrm{UFC} / \mathrm{mL}$. As pesquisas de proteolíticos e proteolíticos-psicrotróficos demonstraram que 14/30 e 5/30, respectivamente, apresentavam cepas na ordem de $10^{3}$ a $10^{6} \mathrm{UFC} / \mathrm{mL}$, de ambos os grupos. Os termodúricos e termodúricos-psicrotróficos ocorreram em apenas duas amostras, com valores que variavam de $10^{3}$ a $10^{4} \mathrm{UFC} / \mathrm{mL}$. As bactérias lácticas foram positivas em $50 \%$ das amostras, sendo que $43,3 \%$ apresentaram contagens superiores a $10^{6} \mathrm{UFC} / \mathrm{mL}$. A pesquisa de lipolíticos demonstrou que $3 / 30$ das amostras apresentaram contagens variando de $10^{4}$ a $10^{6} \mathrm{UFC} / \mathrm{mL}$. Bolores e leveduras foram identificados em apenas duas amostras, ambas com contagens da ordem de $10^{3}$ a $10^{4} \mathrm{UFC} / \mathrm{mL}$. O Staphylococcus coagulase positiva (aureus) foi verificado em nove amostras, com contagens variando de $10^{3}$ a $10^{6} \mathrm{UFC} / \mathrm{mL}$. Verificou-se 
Tabela 1 - Distribuição percentual das amostras contaminadas com os diversos microrganismos/grupos de acordo com a carga microbiana

\begin{tabular}{|c|c|c|c|c|c|c|c|c|c|}
\hline \multirow[b]{2}{*}{ Microrganismos/grupos } & \multicolumn{9}{|c|}{ Contagem de microorganismos } \\
\hline & Ausência & $10^{0}-10^{1}$ & $10^{1}-10^{2}$ & $10^{2}-10^{3}$ & $10^{3}-10^{4}$ & $10^{4}-10^{5}$ & $10^{5}-10^{6}$ & $10^{6}-10^{7}$ & $>10^{7}$ \\
\hline Mesófilos & 3,33 & 0,00 & 0,00 & 0,00 & 0,00 & 10,00 & 26,67 & 13,33 & 46,67 \\
\hline Psicrotróficos & 8,33 & 0,00 & 0,00 & 0,00 & 8,33 & 8,33 & 33,33 & 33,33 & 8,33 \\
\hline Proteolíticos & 6,67 & 0,00 & 0,00 & 0,00 & 6,67 & 26,67 & 20,00 & 26,67 & 13,33 \\
\hline Proteolíticos-psicrotróficos & 16,67 & 0,00 & 0,00 & 0,00 & 0,00 & 16,67 & 50,00 & 0,00 & 16,67 \\
\hline Termodúricos & 33,33 & 0,00 & 0,00 & 0,00 & 0,00 & 66,67 & 0,00 & 0,00 & 0,00 \\
\hline Termodúricos-psicrotróficos & 100,00 & 0,00 & 0,00 & 0,00 & 0,00 & 0,00 & 0,00 & 0,00 & 0,00 \\
\hline Bactérias lácticas & 6,25 & 0,00 & 0,00 & 0,00 & 6,25 & 31,25 & 37,50 & 12,50 & 6,25 \\
\hline Lipolíticos & 25,00 & 0,00 & 0,00 & 0,00 & 00,00 & 50,00 & 0,00 & 25,00 & 0,00 \\
\hline Bolores e leveduras & 25,00 & 0,00 & 0,00 & 0,00 & 00,00 & 75,00 & 0,00 & 0,00 & 0,00 \\
\hline Staphylococcus aureus & 12,50 & 0,00 & 0,00 & 0,00 & 12,50 & 37,50 & 37,50 & 0,00 & 0,00 \\
\hline Coliformes totais & 5,88 & 0,00 & 0,00 & 0,00 & 5,88 & 88,24 & 0,00 & 0,00 & 0,00 \\
\hline Coliformes fecais & 16,67 & 0,00 & 0,00 & 0,00 & 16,67 & 66,67 & 0,00 & 0,00 & 0,00 \\
\hline
\end{tabular}

que 16 amostras apresentavam coliformes totais, com contagens que variaram de $10^{4}$ a $10^{6} \mathrm{UFC} / \mathrm{mL}$. Já os coliformes termotolerantes foram detectados em cinco amostras, com contagens que variaram de $10^{3}$ a $10^{4} \mathrm{UFC} / \mathrm{mL}$.

\section{Discussão}

A detecção de aeróbios mesófilos com contagens superiores a $10^{4} \mathrm{UFC} / \mathrm{mL}$ em $80 \%$ das amostras analisadas evidencia elevado grau de contaminação do leite ordenhado, levando a crer que tais microrganismos encontram condições favoráveis para seu crescimento devido à quebra das boas práticas de manipulação ${ }^{1}$.

A positividade para psicrotróficos em $36,7 \%$ das amostras indica problemas na estocagem a baixas temperaturas $^{9,10}$. A detecção de microrganismos proteolíticos e proteolíticos-psicrotróficos ocorreu em 46,7 e 16,7\%, respectivamente. A presença de termodúricos e termodúricospsicrotróficos em $6,7 \%$ das amostras sugere problemas de manipulação ou na estocagem sobre refrigeração dessas amostras ${ }^{7}$, já que esses microrganismos são contaminantes secundários.

As bactérias lácticas ocorreram em 50\% das amostras, o que indica condições para a multiplicação desses microrganismos fermentadores, que reduzem o pH do produto, com conseqüente perda de cálcio e fósforo ${ }^{11}$.

As bactérias lipolíticas promovem o desenvolvimento de ranço hidrolítico, facilmente perceptível já em sua fase inicial, devido ao forte odor de sabão de $\operatorname{coco}^{1}$. Esse fenômeno ocorreu em $10 \%$ das amostras. Já os bolores e leveduras ocorreram em duas amostras, refletindo higiene inadequada por parte das doadoras ou dos utensílios utilizados ${ }^{7,12,13}$. A contaminação por S. aureus ocorreu em $30 \%$ das amostras, sendo freqüente a associação desse microorganismo com toxinfecções alimentares ${ }^{14}$.

A presença de coliformes totais indica más condições higiênico-sanitárias. O fato de 53,3\% das amostras apresentarem tais microrganismos sugere que houve quebra das boas práticas de manipulação do leite. A detecção de coliformes termotolerantes em $31,2 \%$ das amostras revela a necessidade de melhor controle higiênico-sanitário na coleta de leite por algumas doadoras ${ }^{15}$.

Concluindo, o presente estudo demonstrou que as amostras rejeitadas pela pesquisa de off-flavor foram expostas a contaminantes secundários, provavelmente em razão de manipulação e/ou estocagem inadequadas ${ }^{1}$. Assim, ratifica-se a importância da pesquisa de off-flavor na seleção e classificação do LHO em BLH. Além disso, a comprovação da contaminação do leite na presença de odores estranhos autoriza os profissionais de saúde a recomendarem que as mães que costumam estocar seu leite em suas casas verifiquem a presença de tais odores antes de oferecê-lo para a criança, descartando todo o leite com odores característicos de deterioração ou contaminação.

\section{Referências}

1. Almeida JA, Guimarães V, Novak FR. Determinação do off-flavor - Normas técnicas - RedeBLH-BR para bancos de leite humano. http://www.redeblh.fiocruz.br/media/seleclas.pdf. Acesso: 17/ 05/07. 
2. Brasil, Ministério da Saúde. Recomendações técnicas para o funcionamento de bancos de leite humano. $4^{\mathrm{a}}$ ed. Brasília, DF: Ministério da Saúde; 2001.

3. Almeida JA, Novak FR. O leite humano: qualidade e controle. In: Santos Jr. LA, Almeida JA, Castro FS, Gomes AL, Kemp C, Machado MM, et al., organizadores. Fisiologia e patologia da lactação. Natal: Sociedade Brasileira de Mastologia; 1995. p. 3142 .

4. ANVISA. Portaria no 171 de 04 de setembro de 2006. Dispõe sobre regulamento técnico para o funcionamento de bancos de leite humano. http://e-legis.anvisa.gov.br/leisref/public/ search.php. Acesso: 17/05/2007.

5. Rede Brasileira de Bancos de Leite Humano. Determinação do off-flavor - método sensorial. http://www.redeblh.fiocruz.br/ media/seleclas.pdf. Acesso: 17/05/2007.

6. Leite F. Amostragem. http://www.teanalitica.com.br. Acesso: 10/02/2006.

7. American Public Health Association (APHA). Compendium of methods for the microbiological examination of foods.4th ed. Washington, DC: APHA; 2002.

8. Silva N, Junqueira VC, Silveira NFA. Manual de métodos de análise microbiológica de alimentos. São Paulo: Varela; 1997.

9. Almeida JA. Qualidade do leite humano coletado e processado em bancos de leite [tese]. Viçosa: Universidade Federal de Viçosa; 1986.
10. Almeida JA, Novak FR, Almeida CH, Serva VB. Avaliação parcial da flora microbiana do LHO no IMIP. Rev Inst Mat Inf Pernambuco. 1989;3:13-6.

11. Novak, FR, Almeida JA, Silva RS. Casca de banana: uma possível fonte de infecção no tratemento de fissures mamilares. J Pediatr (Rio J). 2003;79:221-6.

12. Rosa CA, Novak FR, Almeida JA, Hagler CC, Hagler AN. Yeasts from human milk collected in Rio de Janeiro, Brazil. Rev Microbiol. $1990 ; 21: 361-3$.

13. Novak FR, Almeida JA, Santos MJ, Wanke B. Contaminação do leite humano ordenhado por fungos miceliais. J Pediatr (Rio J). 2002; 78:197-201.

14. Novak FR, Almeida JA, Warken MB, Ferreira-Carvalho BT, Hagler AN. Methicillin-resistant Staphylococcus aureus in human milk. Mem Inst Oswaldo Cruz. 2000;95:29-33.

15. Novak FR, Almeida JA. Teste alternativo para detecção de coliformes em leite humano ordenhado. J Pediatr (Rio J). 2002; 78:193-6.

Correspondência:

Franz R. Novak

Rua Silveira Martins, 68/205, Bloco 2, Flamengo

CEP 22221-000 - Rio de Janeiro, RJ

Tel.: (21) 2554.1858

Fax: (21) 2553.9662

E-mail: franz@fiocruz.br 